\title{
NITRIC OXIDE REGULATED IMPROVEMENT IN GROWTH AND YIELD OF RICE PLANTS GROWN UNDER SALINITY STRESS: ANTIOXIDANT DEFENSE SYSTEM
}

\author{
HABIB, N. ${ }^{1}-$ AKRAM, M. S. ${ }^{1}-$ JAVEd, M. T. ${ }^{1}-$ AZEem, M. ${ }^{1}-$ Ali, Q. ${ }^{1 *}-$ ShAHEen, H. L. ${ }^{1}-$ \\ ASHRAF, M. ${ }^{2}$ \\ ${ }^{I}$ Department of Botany, Government College University, Faisalabad-38040, Pakistan \\ ${ }^{2}$ Pakistan Science Foundation, Islamabad, Pakistan \\ *Corresponding author \\ e-mail:qasimbot_uaf@yahoo.com \\ (tel: +92-41-9201488) \\ (Received 27 $7^{\text {th }}$ Apr 2016; accepted 22 $2^{\text {nd }}$ Jul 2016)
}

\begin{abstract}
The current work assessed the effects of exogenously applied sodium nitroprusside (SNP) on rice growth and yield under salt stress. Salt stress induced a significant reduction in biomass and grain yield while increased the plant proline, ascorbic acid, $\mathrm{H}_{2} \mathrm{O}_{2}$ and MDA contents in all studied cultivars. SOD, POD and CAT activities also significantly increased in salt stressed plants; however, the total phenolics content decreased. Application of SNP as seed priming reduced the adverse effects of salinity on plant biomass production and grain yield, while the accumulation of MDA and $\mathrm{H}_{2} \mathrm{O}_{2}$ decreased. Of different SNP levels, $0.1 \mathrm{mM}$ regime was more effective in reducing the negative effects of salinity. Among fine rice cultivars, Shaheen basmati performed better, while among coarse rice cultivars the performance of IRRI-6 was better to exogenously applied $0.1 \mathrm{mM} \mathrm{SNP.} \mathrm{We} \mathrm{concluded} \mathrm{that} \mathrm{exogenous}$ application of SNP up-regulated the antioxidative defense mechanism in salt stressed rice plants which resulted in better yield.
\end{abstract}

Keywords: antioxidative potential, biomass, grain yield, nitric oxide, Oryza sativa L.

\section{Introduction}

Reactive oxygen species (ROS) induced lipid peroxidation under salt stressed environment is a major restricting factor for better plant growth and development (Ashraf and Foolad, 2007; Ashraf, 2009; Sian et al., 2015). Important ROS such as ${ }^{1} \mathrm{O}_{2}$, $\mathrm{O}_{2}^{-}, \mathrm{OH}^{-}$, and $\mathrm{H}_{2} \mathrm{O}_{2}$ being highly reactive in nature, can react with vital metabolites and macro-molecules in cells including photosynthetic pigments, lipids, proteins and DNA (Ashraf, 2009; Sian et al., 2015). Among various cell organelles, the major sites for ROS production are the chloroplast, mitochondria, vacuole and microbodies (Ashraf, 2009). The ROS can initiate a series of destructive processes including the inactivation of antioxidative enzymes (Tanou et al., 2009).

Plants possess an antioxidant defense mechanism to detoxify and scavenge the ROS. Among various antioxidants, flavonoids, tocopherols, phenolics, glutathione, carotenoids and ascorbic acid are non-enzymatic antioxidants; while peroxidase (POD), catalase (CAT), superoxide dismutase (SOD), glutathione reductase (GR), and ascorbate peroxidase (APX) are enzymatic ones (Ashraf, 2009; Ali and Ashraf, 2011). Of different ROS, production of hydrogen peroxide $\left(\mathrm{H}_{2} \mathrm{O}_{2}\right)$ acts as a secondary messenger and helps the plants to rapidly adjust under stressful environmental conditions and mediates defense responses (Miller et al., 2010) but only at low concentrations. Hydrogen peroxide an important ROS also acts as a secondary messenger in low 
concentration, activates enzymatic antioxidative defense mechanism (Tanou et al., 2009; Hernandez et al., 2010), facilitates the stability of SOS1 mRNA and $\mathrm{Na}^{+}$ detoxification under salinity (Chung et al., 2008). Under stressed conditions, such as $\mathrm{NaCl}$ salinity, over-production of $\mathrm{H}_{2} \mathrm{O}_{2}$ directly causes oxidative damages to cellular membranes (Miller et al., 2010).

Among various groups of plant secondary metabolites, phenolics and AsA are important with both biological and antioxidant properties (Posmyk et al., 2009; Ali et al., 2013). The activity of phenolics as an antioxidant metabolite is due to its greater radical stabilization and proton donating ability (Rice-Evans et al., 1996). Plant phenolic content has been reported to be affected under different abiotic stresses including salinity (Ashraf et al., 2010; Jamil et al., 2015). Similarly, AsA also plays its role not only as an important non-enzymatic antioxidant; also contribute efficiently in the completion of enzymatic antioxidation.

The content of MDA can be used as an effective indication to judge the salt tolerance ability of different cultivars (Sairam et al., 2005). Studies reveal that less accumulation of MDA is an indication for improved tolerance against salts stress (Liang et al., 2003; Brankova et al., 2005; Ruiz et al., 2005), because its increased content under salt stress resulted in stunted growth in the plants of sesame (Koca et al., 2007) and tomato (Li, 2009).

Alterations in plant water relations under salt stress are the major obstacle for normal plant growth (Habib et al., 2014). To overcome such problems, plants have adapted a special phenomenon for the accumulation of different osmolytes. It has been reported that among different organic compounds that take part in plant osmotic adjustment, proline is not only an osmoregulator but also an important ROS scavenger (Ashraf and Foolad, 2007). Increased accumulation of proline is a general phenomenon under salt stress, however more accumulation takes places in salt tolerant plants in comparison with the sensitive ones (Ashraf and Foolad, 2007; Habib et al., 2012). Therefore, the amount of proline accumulated could be taken as an important index of salinity tolerance (Ashraf and Foolad, 2007). Different plant species have different potential to tackle the adversative effects of salinity regarding the accumulation and/or synthesis of different organic compounds but several high yielding crop cultivars are not well investigated in this regard (Ali and Ashraf, 2011). So, different techniques are being used for the last two decades for the induction of salt tolerance in these crops and have been found effective to some extent (Ashraf and Foolad, 2007). Use of different chemicals exogenously such as foliar spray or their use as pre-sowing seed treatment is one such technique. Of these exogenously applied compounds, SNP is one such compound (Zhang et al., 2006; Habib et al., 2010). It acts as a free radical which is lipophilic and volatile in nature (Hayat et al., 2010). Apart from its regulatory roles in plants, such as in improving seed germination and seedling growth (Zhang et al., 2006; Habib et al., 2010), it also plays a protective role against different abiotic stresses including water stress (Gracia-Mata and Lamattina, 2001) and salinity (Zhao et al., 2007; Zheng et al., 2009; Habib et al., 2010). Under salinity the different protective role of nitric oxide include the improvement in chlorophyll pigments, gas exchange attributes, and PS-II efficiency (Habib et al., 2013). Its role as protective agent in salinity has been described in wheat (Zheng et al., 2009) and maize (Zhang et al., 2006), where it actively took part in increasing the antioxidant enzymes activity and the activities of proton pumps respectively. 
As there are reports available in literature about the protective role of $\mathrm{NO}_{2}$ against the damages caused by salt stress in crop plants but very few is available about its role in seed yield increments especially in rice in relation with plant oxidative defense mechanism. Therefore the present study was considered with the objective to find out the effects of varying regimes of exogenously applied SNP on the yield of different rice cultivars in relation with its role in enhancing the plant antioxidative capacity with special reference to some enzymatic and non-enzymatic compounds under salinity.

\section{Materials and Methods}

The experiment was conducted under natural conditions (day length $13.8 \mathrm{~h}$; relative humidity $45.2 \%$; PPFD, $1275 \mu \mathrm{mol} \mathrm{m} \mathrm{m}^{-2} \mathrm{~s}^{-1}$; the day and night temperatures were $36 \pm 3$ ${ }^{\circ} \mathrm{C}$ and $27 \pm 2{ }^{\circ} \mathrm{C}$ respectively). The total four cultivars of rice were used in this study, two of these were fine rice (Basmati PB-95 and Bsmati Shaheen), while other two (IRRI-6 and KS-282) were coarse rice cultivars. Before treatment the seeds were surface sterilized with $1 \%$ solution of $\mathrm{NaOCl}$ for 5 min then washed the seeds thrice with $\mathrm{ddH}_{2} \mathrm{O}$. The seeds were subsequently soaked in varying levels $(0,0.1$, and $0.2 \mathrm{mM})$ of SNP for $20 \mathrm{~h}$. Thirty days old seedlings (prepared separately) were transplanted in tubs (each filled with $16 \mathrm{~kg}$ of sandy loam soil) arranged in CRD with four replicates of each treatment. The seedlings were established after one week of transplant and salt treatment $(0$ and $80 \mathrm{mM}$ of $\mathrm{NaCl})$ was applied by increasing the level gradually. The experiment was repeated to validate the results. Data for growth and biochemical attributes was recorded after 30 days of the start of $\mathrm{NaCl}$ treatment, while yield attributes were estimated at maturity.

\section{Determination of the activity of different antioxidant enzymes}

\section{Enzyme extraction}

To determine the activity of various antioxidant enzymes, enzyme extracts were prepared following the method described by Ali and Ashraf (2011).

\section{Estimation of the activities of SOD, POD and CAT}

The SOD activity was determined following the method of Giannopolitis and Ries (1977) with some modifications while for estimating the activity of CAT and POD the method of Chance and Maehly (1955) was followed with some modifications.

\section{Leaf ascorbic acid contents}

Leaf ascorbic acid content was determined by following a method described by Mukherjee and Choudhuri (1983). Varying levels of pure AsA were used to make the standard curves for measuring the AsA content in the mixture. While the leaf total phenolic contents was measured according to a method described by Julkenen-Titto (1985).

\section{Hydrogen peroxide}

Hydrogen peroxide $\left(\mathrm{H}_{2} \mathrm{O}_{2}\right)$ content was determined following the method described by Velikova et al. (2000). 
Malondialdehyde (MDA)

The method of Carmak and Horst (1991) was used to determine the MDA content.

\section{Proline content}

Leaf proline content was determined by following a method described by Bates et al. (1973).

\section{Yield attributes}

Different yield attributes such as number of tillers, weight of hundred grains and grain yield per plant were estimated at maturity after drying properly the spikes under natural sun light.

\section{Statistical analysis}

The experiment was arranged in a completely randomized design (CRD) with four replicates and the data so generated for different attributes was analyzed using a software named CoSTAT V 6.3 (developed by, Cohort software, Berkeley, California, USA).

\section{Results}

\section{Morphology and growth}

Shoot and root fresh and dry biomass significantly decreased in studied rice cultivars grown under salt stress (Fig. 1; Table 1). Exogenous application of SNP as seed treatment was found effective in increasing the fresh and dry biomass of shoot and root in all rice cultivars under non-stressed and salt stressed conditions. For shoot fresh and dry weights, $0.1 \mathrm{mM}$ SNP was more effective under both non-saline and saline conditions, while in relation with root fresh and dry biomass both SNP levels were found equally effective. Among rice cultivars, IRRI-6 and Shaheen Basmati exhibited higher shoot fresh and dry weights under salt stress, while higher root fresh and dry weights were observed in cvs. IRRI-6 and KS-282.

Imposition of saline stress also significantly reduced the shoot length of all rice cultivars (Fig. 1; Table 1). Exogenous application of different regimes of SNP as presowing seed treatment significantly reduced the adverse effects of rooting medium salinity on shoot length in all rice cultivars. Of different SNP levels, more increase in shoot length was found in plants raised from seeds treated with $0.1 \mathrm{mM}$ SNP under both non-saline and saline conditions. Maximum increase in shoot length was recorded in cv. Shaheen Basmati under saline conditions, however, under non-saline conditions, maximum increase in shoot length was observed in Basmati PB-95.

\section{Enzymatic antioxidants}

The activity of antioxidant enzyme superoxide dismutase (SOD) was increased significantly in all rice cultivars grown under salinity (Fig. 2; Table 1). Pre-sowing seed treatment with different SNP regimes further increased the SOD activity in all rice cultivars under non-saline and salt stressed conditions and the maximal increase in SOD activity due to SNP seed treatment was found in plants raised from seeds 
treated with $0.1 \mathrm{mM}$ level of SNP. However in rice cultivar IRRI-6 both SNP regimes equally increased the SOD activity under non-saline and saline conditions. Comparatively SNP-induced more increase in SOD activity was found in cv. Shaheen Basmati under salinity stress.
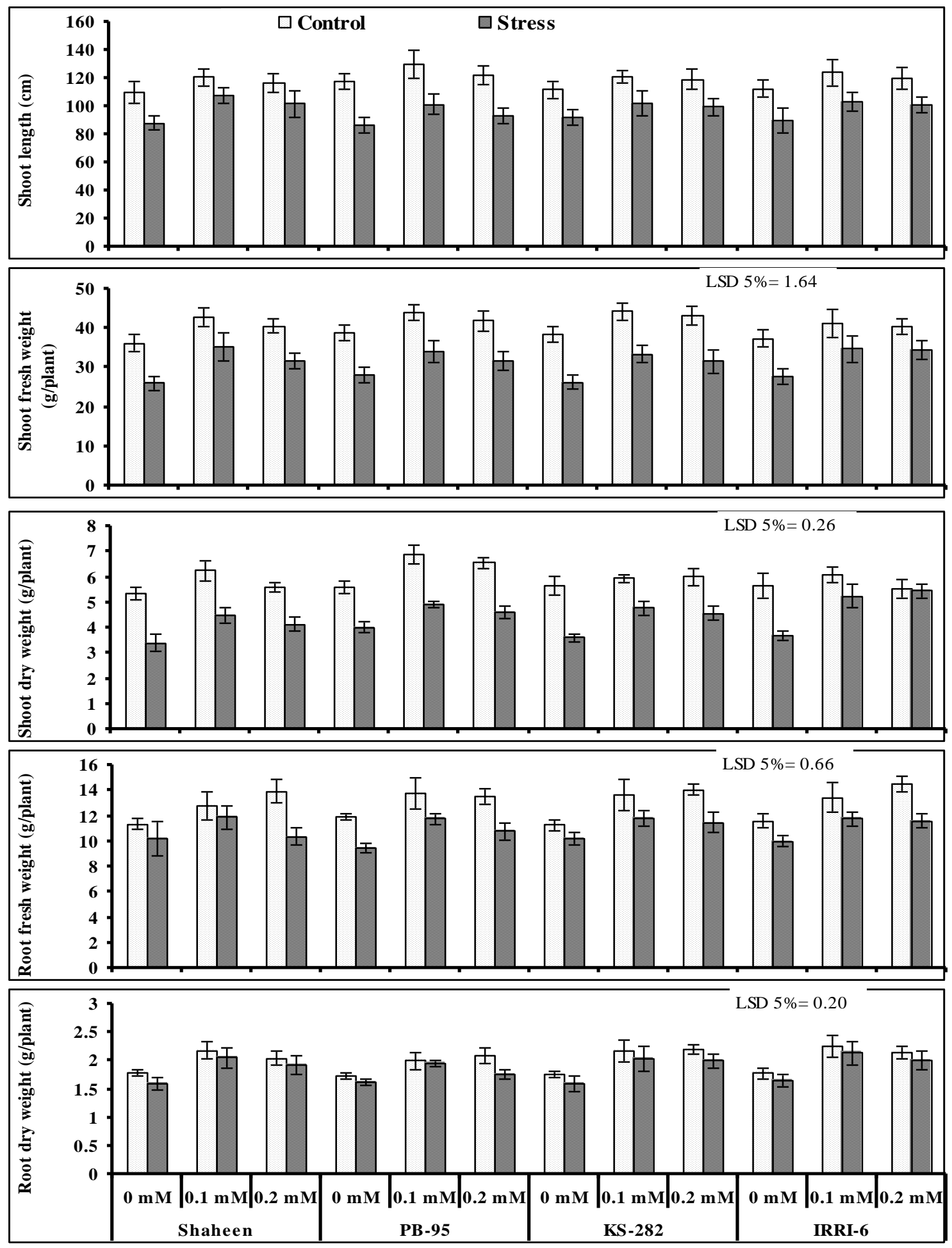

Figure 1. Growth attributes of four rice cultivars affected by pre-sowing seed treatment with different regimes of SNP grown under salt stress (mean \pm SE) 
Table 1. Mean squares from statistical analysis of the data for studied attributes of rice plants of four rice cultivars influenced by exogenouslyapplied SNP under salt stress

\begin{tabular}{|c|c|c|c|c|c|c|c|}
\hline SOV & df & $\begin{array}{l}\text { Shoot fresh } \\
\text { weight }\end{array}$ & $\begin{array}{l}\text { Shoot dry } \\
\text { weight }\end{array}$ & $\begin{array}{l}\text { Root fresh } \\
\text { weight }\end{array}$ & Root dry weight & Shoot Length & $\begin{array}{l}\text { Number of } \\
\text { tillers }\end{array}$ \\
\hline Variety (V) & 3 & $15.16 \mathrm{~ns}$ & $1.74 * * *$ & $2.40 \mathrm{~ns}$ & $0.208 \mathrm{~ns}$ & $50.04 *$ & $0.177 \mathrm{~ns}$ \\
\hline Salinity (S) & 1 & $2303.40 * * *$ & $65.50 * * *$ & $85.10 * * *$ & $0.432 *$ & $10901.34 * * *$ & $29.260 * * *$ \\
\hline $\mathrm{NO}(\mathrm{N})$ & 2 & $26.60 * * *$ & $5.64 * * *$ & $26.31 * * *$ & $2.346 * * *$ & $565.36 * * *$ & $5.281 * *$ \\
\hline $\mathrm{V} \times \mathrm{S}$ & 3 & $23.90 \mathrm{~ns}$ & $1.77 * * *$ & $1.10 \mathrm{~ns}$ & $0.239 \mathrm{~ns}$ & $31.76 \mathrm{~ns}$ & $0.454 \mathrm{~ns}$ \\
\hline $\mathrm{V} \times \mathrm{N}$ & 6 & $4.31 \mathrm{~ns}$ & $0.42 \mathrm{~ns}$ & $0.09 \mathrm{~ns}$ & $0.017 \mathrm{~ns}$ & $7.63 \mathrm{~ns}$ & $0.072 \mathrm{~ns}$ \\
\hline $\mathrm{S} \times \mathrm{N}$ & 2 & $3.91 \mathrm{~ns}$ & $0.91 *$ & $7.44 *$ & $0.136 \mathrm{~ns}$ & $132.01 *$ & $0.947 \mathrm{~ns}$ \\
\hline $\mathrm{V} \times \mathrm{S} \times \mathrm{N}$ & 9 & $3.24 \mathrm{~ns}$ & $0.50 \mathrm{~ns}$ & $1.26 \mathrm{~ns}$ & $0.036 \mathrm{~ns}$ & $9.38 \mathrm{~ns}$ & $0.434 \mathrm{~ns}$ \\
\hline Error & 72 & 10.77 & 0.26 & 1.75 & 0.159 & 35.72 & 0.802 \\
\hline SOV & df & SOD & POD & CAT & $\mathrm{H}_{2} \mathrm{O}_{2}$ & AsA & Proline \\
\hline Variety (V) & 3 & $0.54 \mathrm{~ns}$ & $0.490 \mathrm{~ns}$ & $0.021 \mathrm{~ns}$ & $18.84 \mathrm{~ns}$ & $7.957 \mathrm{~ns}$ & $1.32 \mathrm{~ns}$ \\
\hline Salinity (S) & 1 & $6850.24 * * *$ & $7228.180 * * *$ & $1587.620 * * *$ & $10157.87 * * *$ & $1.227 * * *$ & 11961.73 *** \\
\hline $\mathrm{NO}(\mathrm{N})$ & 2 & $105.59 * * *$ & $100.730 * * *$ & $59.730 * * *$ & $274.21 * * *$ & $0.107 * * *$ & $126.41 * * *$ \\
\hline $\mathrm{V} \times \mathrm{S}$ & 3 & $0.58 \mathrm{~ns}$ & $0.013 \mathrm{~ns}$ & $0.022 \mathrm{~ns}$ & $17.54 \mathrm{~ns}$ & $5.044 \mathrm{~ns}$ & $4.11 \mathrm{~ns}$ \\
\hline $\mathrm{V} \times \mathrm{N}$ & 6 & $0.53 \mathrm{~ns}$ & $0.033 \mathrm{~ns}$ & $0.011 \mathrm{~ns}$ & $1.86 \mathrm{~ns}$ & $3.721 \mathrm{~ns}$ & $0.59 \mathrm{~ns}$ \\
\hline $\mathrm{S} \times \mathrm{N}$ & 2 & $28.06 * * *$ & $19.576 * * *$ & $14.410 * * *$ & $22.51 \mathrm{~ns}$ & $0.003 \mathrm{~ns}$ & $31.56 *$ \\
\hline $\mathrm{V} \times \mathrm{S} \times \mathrm{N}$ & 9 & $0.28 \mathrm{~ns}$ & $0.021 \mathrm{~ns}$ & $0.006 \mathrm{~ns}$ & $5.62 \mathrm{~ns}$ & $0.001 \mathrm{~ns}$ & $1.97 \mathrm{~ns}$ \\
\hline Error & 72 & 1.94 & 1.661 & 0.178 & 18.85 & 0.002 & 6.54 \\
\hline SOV & df & MDA & Total phenolics & $\begin{array}{l}100 \text { grain } \\
\text { weight }\end{array}$ & $\begin{array}{l}\text { Total grain } \\
\text { weight/plant }\end{array}$ & & \\
\hline Variety (V) & 3 & $3.21 \mathrm{~ns}$ & $0.056 \mathrm{~ns}$ & $7.957 \mathrm{~ns}$ & $0.056 \mathrm{~ns}$ & & \\
\hline Salinity (S) & 1 & $25734.95 * * *$ & $1229.801 * * *$ & $1.227 * * *$ & $1229.801 * * *$ & & \\
\hline $\mathrm{NO}(\mathrm{N})$ & 2 & $276.74 * * *$ & $16.510 * * *$ & $0.107 * * *$ & $16.510 * * *$ & & \\
\hline$V \times S$ & 3 & $19.64 \mathrm{~ns}$ & $0.128 \mathrm{~ns}$ & $5.044 \mathrm{~ns}$ & $0.128 \mathrm{~ns}$ & & \\
\hline $\mathrm{V} \times \mathrm{N}$ & 6 & $3.46 \mathrm{~ns}$ & $0.055 \mathrm{~ns}$ & $3.721 \mathrm{~ns}$ & $0.055 \mathrm{~ns}$ & & \\
\hline $\mathrm{S} \times \mathrm{N}$ & 2 & $32.43 \mathrm{~ns}$ & $1.923 * * *$ & $0.003 \mathrm{~ns}$ & $1.923 * * *$ & & \\
\hline$V \times S \times N$ & 9 & $1.87 \mathrm{~ns}$ & $0.012 \mathrm{~ns}$ & $0.001 \mathrm{~ns}$ & $0.012 \mathrm{~ns}$ & & \\
\hline Error & 72 & 12.17 & 0.210 & 0.002 & 0.210 & & \\
\hline
\end{tabular}



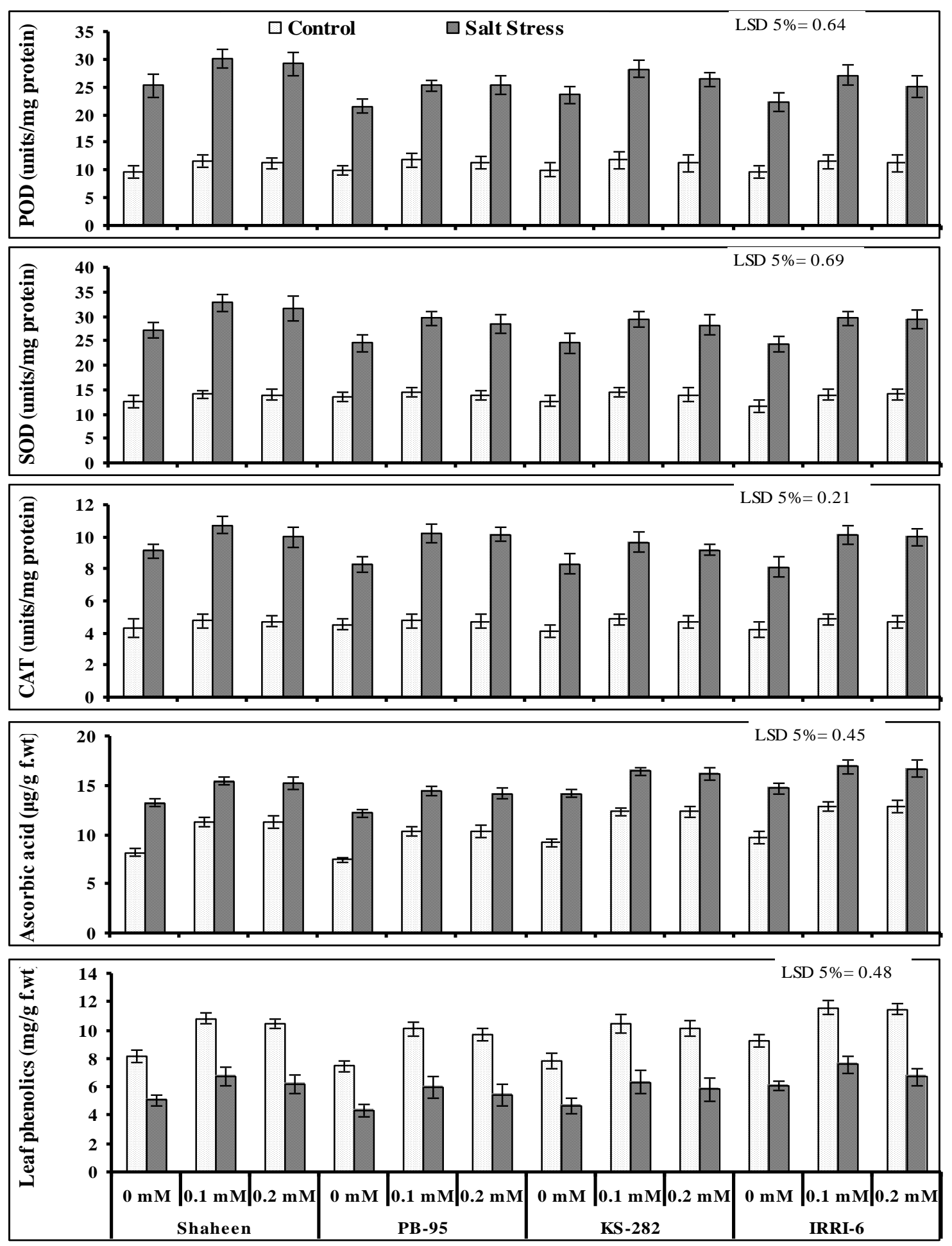

Figure 2. Enzymatic and non-enzymatic antioxidants of four rice cultivars affected by presowing seed treatment with different regimes of SNP grown under salt stress (mean \pm SE)

Rooting medium salinity caused a significant increase in leaf POD activity in plants of all rice cultivars (Fig. 2; Table 1). Exogenous SNP treatment further increased the POD activity in plants of all rice cultivars grown under both saline and non-saline 
conditions and more increase in POD activity was recorded in plants raised from seeds treated with $0.1 \mathrm{mM}$ SNP regime. Among all rice cultivars the maximal increase in POD activity due to SNP treatment was found in cv. Shaheen Basmati and IRRI-6 under salinity stress.

Like SOD and POD, the leaf CAT activity was also enhanced significantly in plants of all rice cultivars when grown under salt stress (Fig. 2; Table 1). The CAT activity was further increased due to SNP seed treatment under salinity. Both regimes of SNP were found equally effective in improving the activity of CAT. SNP-induced more increase in leaf CAT activity was recorded in cvs. Shaheen Basmati and IRRI-6 as compared with other rice cultivars under salinity.

\section{Non-enzymatic antioxidants}

Leaf ascorbic acid content in all rice cultivars was enhanced significantly when grown under salt stress (Fig. 2; Table 1). Sodium nitroprusside treatment as seed priming further enhanced the leaf ascorbic acid content under salt stress and both SNP levels were found equally effective in this regard. However, under non-saline conditions this increase in leaf ascorbic acid content was more in plants raised from seeds treated with $0.2 \mathrm{mM}$ regime of SNP. More increase in leaf ascorbic acid due to SNP seed treatment was found in cvs. Shaheen Basmati and IRRI-6 under saline and non-saline conditions.

Leaf total phenolics content reduced significantly in all studied rice cultivars due to rooting medium salinity (Fig. 2; Table 1). Seed priming with SNP was effective in improving the total phenolic content in both saline and non-stressed conditions. Although seed priming with both SNP regimes $(0.1$ and $0.2 \mathrm{mM})$ found equally effective in increasing total phenolic content, however, under salinity $0.1 \mathrm{mM}$ SNP regime as seed priming was found more effective Comparatively higher total phenolic content was found in cvs. IRRI-6 and KS-282 under non-saline and saline conditions.

Rooting medium salinity increased the leaf proline content in all studied rice cultivars (Fig. 3; Table 1). A further increase in leaf proline content was found in plants of all rice cultivars that grown from seeds pre-treated with both SNP regimes. This increase in leaf proline due to SNP priming was found at both SNP regimes in all rice cultivars under salt stress. Comparatively higher increase in proline content was observed in cvs. Shaheen Basmati and IRRI-6 as compared with other rice cultivars.

\section{$M D A$ and $\mathrm{H}_{2} \mathrm{O}_{2}$ content}

A significant increase in leaf MDA was recorded in all rice cultivars due to rooting medium salinity (Fig. 3; Table 1). Comparatively less increase in MDA due to rooting medium salinity was recorded in cvs. Shaheen basmati and IRRI-6 as compared with other rice cultivars. A significant decrease in leaf MDA content was found in rice plants of all cultivars that were grown from seeds primed with SNP. However, this decrease was found only at $0.1 \mathrm{mM}$ level of SNP.

Imposition of salt stress significantly increased the leaf $\mathrm{H}_{2} \mathrm{O}_{2}$ content (Fig. 3; Table 1). Exogenous SNP application was found effective in reducing the $\mathrm{H}_{2} \mathrm{O}_{2}$ content in all rice cultivars. Seed priming with both SNP levels $(0.1$ and $0.2 \mathrm{mM})$ were found equally effective in reducing the leaf $\mathrm{H}_{2} \mathrm{O}_{2}$ content in all rice cultivars. 

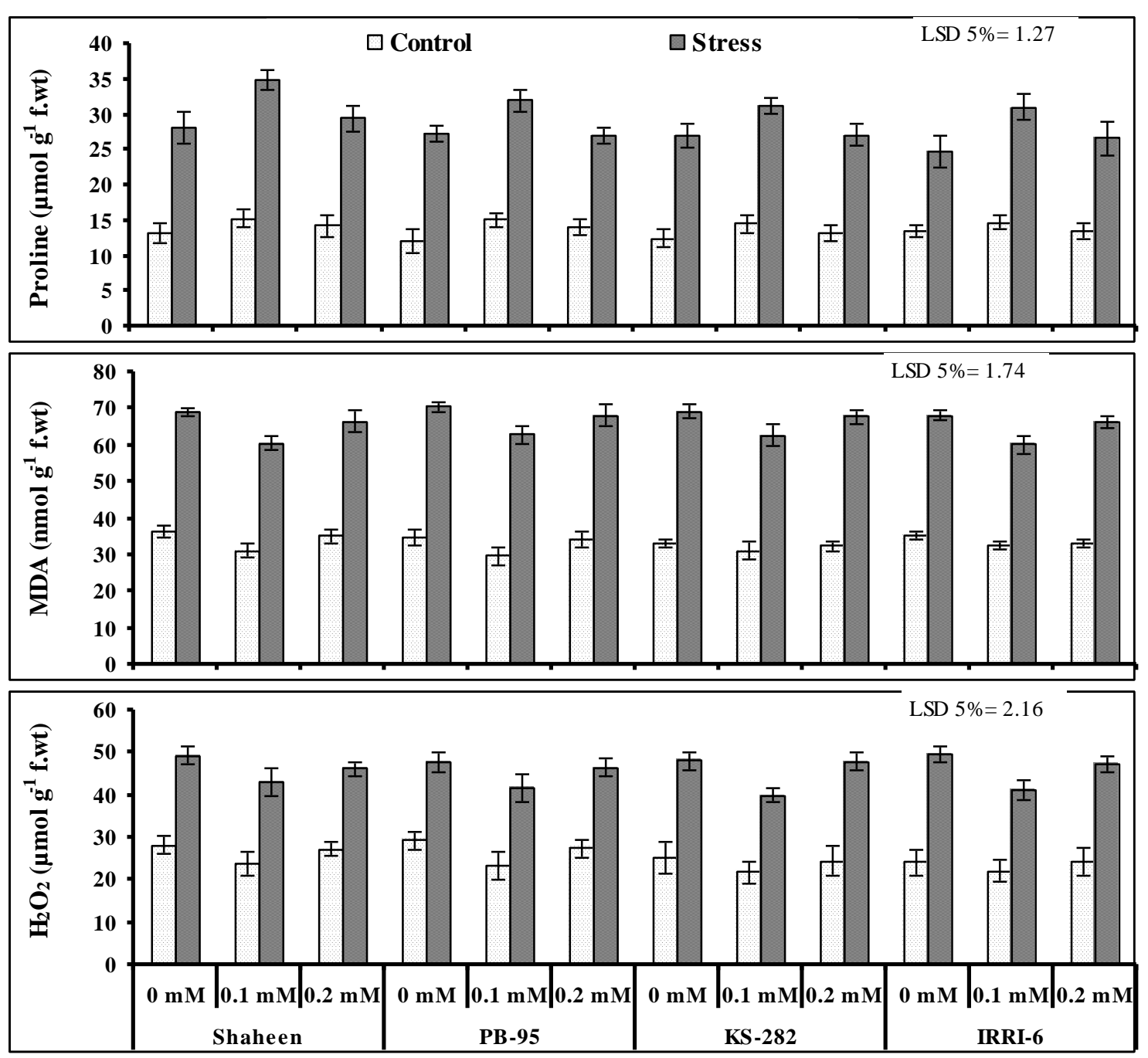

Figure 3. Leaf proline, $\mathrm{MDA}$ and $\mathrm{H}_{2} \mathrm{O}_{2}$ content of four rice cultivars affected by pre-sowing seed treatment with different regimes of SNP grown under salt stress (mean $\pm S E$ )

\section{Yield attributes}

Like other growth and physico-chemical parameters, number of tillers was also significantly reduced due to rooting medium salinity in all rice cultivars (Fig 4; Table 1). A significant ameliorative effect of seed priming with SNP was found on number of tillers under salt stress in all rice cultivars and both SNP levels $(0.1$ and $0.2 \mathrm{mM})$ were found equally effective in this regard.

Imposition of salt stress decreased the hundred grain weight in all rice cultivars (Fig. 4; Table 1). Seed priming with only lower level $(0.1 \mathrm{mM})$ of SNP was found effective in reducing the adverse effects of salt stress on hundred grain weight in all rice cultivars. Comparatively more amelioration on hundred grain weight due to SNP seed priming was recorded in cvs. KS-282 and IRRI-6

Grain yield per plant was also decreased significantly in all rice cultivars due to rooting medium salinity (Fig. 4; Table 1). Seed priming with SNP was found effective in reducing the adverse effects of salt stress on grain yield per plant in all rice cultivars. Of all SNP levels, $0.1 \mathrm{mM}$ was more effective in reducing the adverse effects of salt 
stress on grain yield per plant. Comparatively SNP-induced this amelioration on grain yield per plant was more in cvs. IRRI-6 and KS-282.
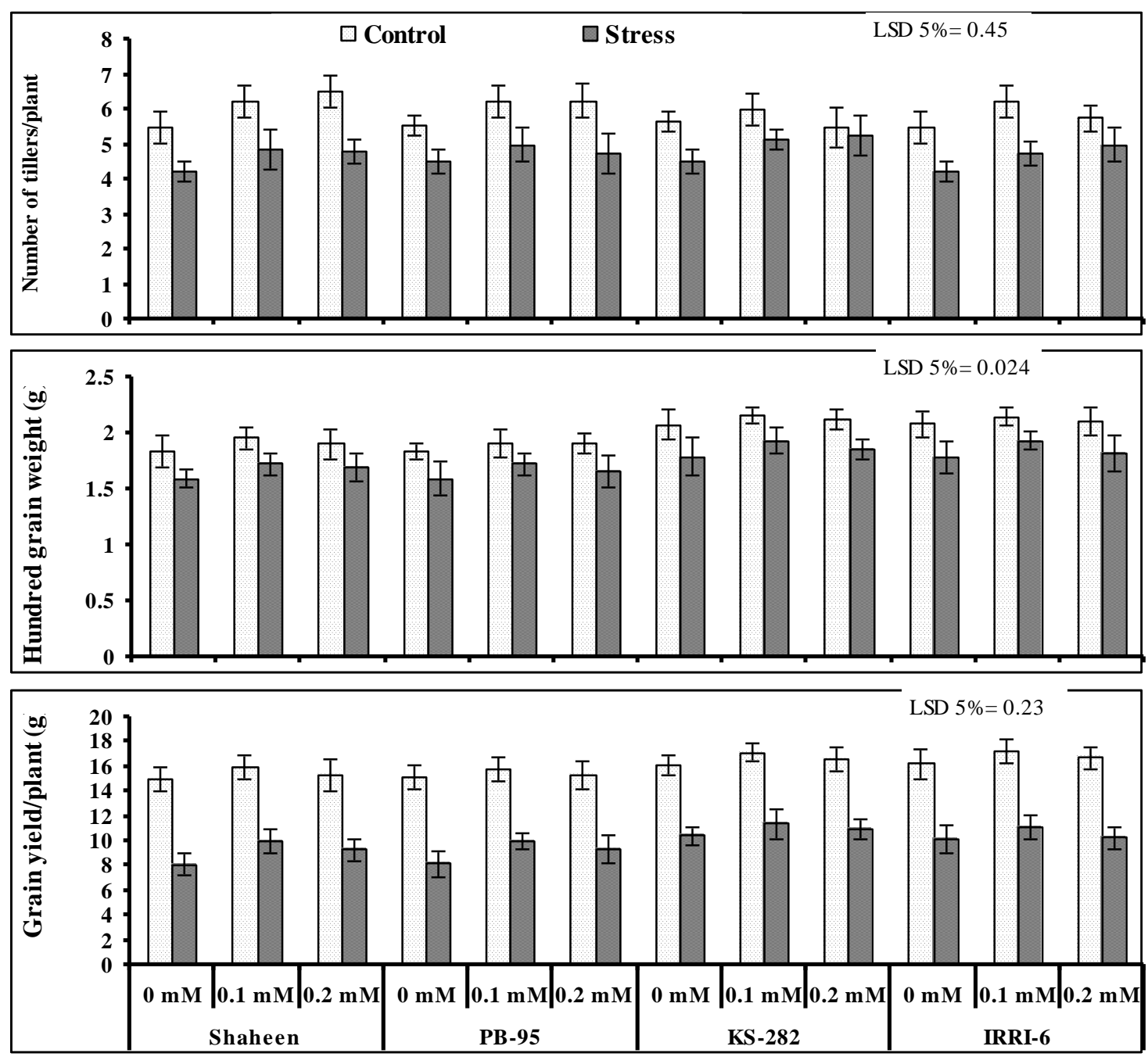

Figure 4. Yield attributes of four rice cultivars affected by pre-sowing seed treatment with different regimes of SNP grown under salt stress (mean $\pm S E$ )

\section{Discussion}

The reduction of yield under adverse environmental conditions including salinity is the result of reduction in plant biomass production and has been the subject of many research studies. This reduction in biomass production under salt stress is the result of metabolic alterations in biochemical and physiological process. These include the disturbances in plant water relations, gas exchange attributes, photosynthetic machinery, as well as the production of ROS in excessive amount (known as oxidative stress). These ROS directly or indirectly damages the cellular components including the membranes, resulting in reduced biomass production (Ali and Ashraf, 2011). Of different ROS, production of $\mathrm{H}_{2} \mathrm{O}_{2}$ is also an important and common phenomenon which is beneficial as a signaling molecule at lower concentrations (Miller et al., 2010). It has been reported that $\mathrm{H}_{2} \mathrm{O}_{2}$ increases the activity of plasma membrane $\mathrm{H}^{+}$- 
ATPase, which could in turn maintain the $\mathrm{K}^{+} / \mathrm{Na}^{+}$homeostasis (Zhang et al., 2007). Moreover, $\mathrm{H}_{2} \mathrm{O}_{2}$ has also been reported to facilitate the SOS1 mRNA stability which helped in $\mathrm{Na}^{+}$detoxification in Arabidopsis (Chung et al., 2008). However, in high concentration $\mathrm{H}_{2} \mathrm{O}_{2}$ directly damages cellular membranes (Miller et al., 2010). Such damages to cellular membranes due to high production of ROS under salt stress results in accumulation of more MDA due to lipid peroxidation that determines the degree of damage to cellular membranes. Such salt-induced lipid peroxidation results in more leaky membrane (Ashraf and Ali, 2008; Sheokand et al., 2010) that results in lower biomass production and plant yield. Salt-induced increase in MDA content due to oxidative stress has been reported in plants such as canola (Ashraf and Ali, 2008), Kosteletzkya virginica (Guo et al., 2009) and wheat (Ashraf et al., 2010). The present findings also depicts that, rooting medium salinity increased the $\mathrm{H}_{2} \mathrm{O}_{2}$ and MDA contents with a reduction in plant biomass production and grain yield in all rice cultivars. Under such conditions, activity of antioxidative defense mechanism i.e. comprised of enzymatic and non-enzymatic antioxidants is effective to scavenge and detoxify the over produced ROS to reduce their damaging effects. However, the activity of these antioxidants differs among species/cultivars which are important in determining the salt tolerance ability among different cultivars of crop plants (Ashraf, 2009; Ashraf et al., 2012).

Apart from exploring inter-cultivar difference for salt tolerance, exogenous application of different compounds are also being extensively used and found effective in improving plant salt tolerance level (Ashraf and Foolad, 2005) by modifying the various physiological and biochemical processes. Similarly like other compounds, protective effects of exogenously applied SNP against salt induced damages in plants have been well documented (Zhang et al., 2006; Zheng et al., 2009; Habib et al., 2010, 2013). Number of reports has already shown the protective effect of $\mathrm{SNP} / \mathrm{NO}_{2}$ against salt-induced membrane lipid peroxidation in plants (Zhang et al., 2006; Shi et al., 2007). It has been found that $\mathrm{NO}_{2}$ helps to prevent ROS-induced membrane damages by

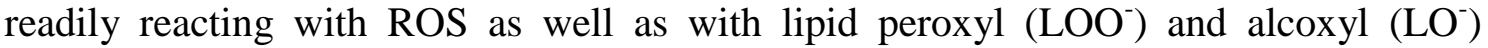
radicals (Sheokand et al., 2010). In present study, exogenous SNP (source of $\mathrm{NO}_{2}$ ) application as seed priming was found effective in decreasing the lipid peroxidation in rice plants grown under salt stress.

Normally $\mathrm{H}_{2} \mathrm{O}_{2}$ production takes places by a reaction of SOD with superoxide, radical while, ascorbate peroxidase (APX) and catalase (CAT) acts as $\mathrm{H}_{2} \mathrm{O}_{2}$ scavengers (Miller et al., 2010). In the present study, exogenous use of SNP was proved effective in improving the activity of enzymatic antioxidant (SOD, POD and CAT). The increase was also in accordance with previous reports in which increased antioxidant enzymes activity due to SNP treatment have been noted in seedlings of wheat (Zeng et al., 2009), mustard green (Zeng et al., 2011) and Brassica campestris (Chang-Li et al., 2011). Moreover, in present study this increase in antioxidative enzyme activities resulted in a decrease in $\mathrm{H}_{2} \mathrm{O}_{2}$ contents with a reduction in MDA accumulation. This decrease in MDA content with a reduction of $\mathrm{H}_{2} \mathrm{O}_{2}$ might be due to enhanced scavenging activity of antioxidant enzymes. Such SNP-applied decrease in leaf $\mathrm{H}_{2} \mathrm{O}_{2}$ under salinity in rice plants is in agreement with the studies has already been reported in Arabidopsis (Zhao et al., 2007) and chickpea (Sheokand et al., 2010) grown under salinity.

Leaf ascorbic acid and phenolic contents have significant roles in many metabolic processes in plants (Jamil et al., 2015). These antioxidative compounds play protective roles against salt-induced oxidative damages by scavenging ROS such as singlet 
oxygen, hydroxyl radical and superoxide (Ashraf and Ali, 2008). In the present study, exogenous SNP treatment was found effective in increasing the leaf ascorbic acid and phenolic content in rice plants grown under salt stress. Such SNP-induced enhanced synthesis of ascorbic acid and phenolic contents could be due to the involvement of NO2 in the activation of cellular antioxidative defence mechanism (Zeng et al., 2011). SNP-induced such increase in leaf ascorbic acid content has also been found in water stressed rice plants (Shehab et al., 2010). Similarly, it has been found that leaf total phenolic content also increased significantly due to exogenous SNP treatment under adverse environmental conditions (Shehab et al., 2010; Buss et al., 2011).

Leaf proline, a well-known secondary metabolite, plays a significant role as osmoprotectant as well as an antioxidant. As an osmotica, it not only actively takes part in cellular water relations under adverse conditions but also protects the cellular membranes by playing role as an antioxidant (Ali and Ashraf, 2011; Ashraf et al., 2012; Habib et al., 2012). In the present study, leaf proline content significantly increased due to exogenous SNP treatment in rice plants, showing its role as plant stress tolerant compound. SNP-induced accumulation in leaf proline has already been reported in Kosteletzkya virginica plants grown under salt stress (Guo et al., 2009).

\section{Conclusions}

It was concluded that the SNP seed priming increased the rice plant growth, grain yield and biomass production by the up-regulation of activities of antioxidant enzymes as well as the contents of non-enzymatic antioxidantive compounds which in turn resulted in enhanced ROS scavenging and reduced lipid peroxidation. The exogenous SNP seed treatment also modulated the proline synthesis/accumulation under salt stress there by reducing the salt-induced toxic effects. Regarding various SNP levels, it was concluded that the lower concentration of SNP $(0.1 \mathrm{mM})$ can be used effectively for better yield in rice cultivated in salt rich areas.

\section{REFERENCES}

[1] Ali, Q., Ashraf, M. (2011a): Exogenously applied glycinebetaine enhances seed and seed oil quality of maize (Zea mays L.) under water deficit conditions. - Environmental and Experimental Botany 71(2): 249-259.

[2] Ali, Q., Ashraf, M. (2011b): Induction of drought tolerance in maize (Zea mays L.) due to exogenous application of trehalose: Growth, photosynthesis, water relations and oxidative defence mechanism. - Journal of Agronomy and Crop Science 197(4): 258-271.

[3] Ali, Q., Anwar, F., Ashraf, M., Saari, N. and Perveen, R. (2013): Ameliorating effects of exogenously applied proline on seed composition, seed oil quality and oil antioxidant activity of maize (Zea mays L.) under drought stress. - International Journal of Molecular Sciences 14: 818-835.

[4] Ashraf, M. (2009): Biotechnological approach of improving plant salt tolerance using antioxidants as markers. - Biotechnological Advances 27: 84-93.

[5] Ashraf, M. and Foolad, M.R. (2007): Roles of glycine betaine and proline in improving plant abiotic-stress resistance. - Environmental and Experimental Botany 59(2): 206-216.

[6] Ashraf, M. and Ali, Q. (2008): Relative membrane permeability and activities of some antioxidant enzymes as the key determinants of salt tolerance in canola (Brassica napus L.). - Environmental and Experimental Botany 63(1-3): 266-273. 
[7] Ashraf, M.A., Ashraf, M. and Ali, Q. (2010): Response of two genetically diverse wheat cultivars to salt stress at different growth stages: leaf lipid peroxidation and phenolic contents. - Pakistan Journal of Botany 42(1): 559-565.

[8] Ashraf, M.A., Ashraf, M. and Shahbaz, M. (2012): Growth stage-based modulation in antioxidant defense system and proline accumulation in two hexaploid wheat (Triticum aestivum L.) cultivars differing in salinity tolerance. - Flora 207: 388-397.

[9] Bates, L.S., Waldren, R.P. and Teare, I.D. (1973): Rapid determination of free proline for water stress studies. - Plant and Soil 39: 205-207.

[10] Brankova, L., Ivanov, S., Alexieva, V. and Karanov, E. (2005): Salt induced alteration in the levels of some oxidative parameters and unspecific defence compounds in leaves of two plant species (cotton and bean) with different sensitivity to salinity. - Comptes rendus de l'Academie bulgare des Sciences 58(11): 1307-1312.

[11] Buss, D.S., Dias, G.B., Santos, M.P., Ventura, J.A. and Fernandes, P.M.B. (2011): Oxidative stress defence response of Carica papaya challenged by nitric oxide, papaya meleira virus and Saccharomyces cerevisiae. - Open Nitric Oxide Journal 3: 55-64.

[12] Carmak, I. and Horst, J.H. 1991: Effects of aluminum on lipid peroxidation, superoxide dismutase, catalase, and peroxidase activities in root tips of soybean (Glycine max). Physiologia Plantarum 83: 463-468.

[13] Chance, B. and Maehly, A.C. (1955): Assay of catalase and peroxidase. - Methods in Enzymology 2: 764-775.

[14] Chang-Li, Z., Man, L. and Min-chao, L. (2011): Physiological effects of exogenous nitric oxide on Brassica campestris ssp. Chinensis L. seedlings under salt stress. - In: Remote Sensing, Environment and Transportation Engineering (RSETE)5149-5152. IEEE.

[15] Chung, J.S., Zhu, J.K., Bressan, R.A., Hasegawa, P.M. and Shi, H. (2008): Reactive oxygen species mediate Na?-induced SOS1 mRNA stability in Arabidopsis. - Plant Journal (53): 554-565.

[16] García-Mata, C. and Lamattina, L. 2001. Nitric oxide induces stomatal closure and enhances the adaptive plant responses against drought stress. - Plant Physiology 126: 1196-1204.

[17] Giannopolitis, C.N. and Ries, S.K. (1977): Superoxide occurrence in higher plants. - Plant Physiology 59: 309-314.

[18] Guo, Y., Tian, Z., Yan, D., Zhang, J. and Qin, P. (2009): Effects of nitric oxide on salt stress tolerance in Kosteletzkya virginica. - Life Science Journal 6: 67-75.

[19] Habib, N., Ashraf, M. and Shahbaz, M. (2013): Effect of exogenously applied nitric oxide on some key physiological attributes of rice (Oryza sativa L.) plants under salt stress. Pakistan Journal of Botany 45(5): 1563-1569.

[20] Habib, N., Ashraf, M. and Ahmad, M.S.A. (2010). Enhancement in seed germinability of rice (Oryza sativa L.) by pre-sowing seed treatment with nitric oxide (NO) under salt stress. - Pakistan Journal of Botany 42(6): 4071-4078.

[21] Habib, N., Ashraf, M., Ali, Q. and Perveen, R. (2012): Response of salt stressed okra (Abelmoschus esculentus Moench) plants to foliar-applied glycine betaine and glycine betaine containing sugarbeet extract. - South African Journal of Botany 83: 151-158.

[22] Habib, N. and M. Ashraf. (2014): Effect of exogenously applied nitric oxide on water relations and ionic composition of rice (Oryza sativa L.) plants under salt stress. Pakistan Journal of Botany 46(1): 111-116.

[23] Hayat, S.S.A., Hasan, M., Mori, Fariduddin, Q. and Ahmad, A. (2010): Nitric oxide: Chemistry, biosynthesis, and physiological role. - In: Hayat, S., Mori, M., Pichtel, J., Ahmad, A. (Eds.) Nitric Oxide in Plant Physiology. GmbH and Co. KGaA, Weinheim, Germany: WILEY-VCH Verlag, pp. 1-16.

[24] Hernandez, M., Fernandez-Garcia, N., Diaz-Vivancos, P. and Olmos, E. (2010): A different role for hydrogen peroxide and the antioxidative system under short and long salt stress in Brassica oleracea roots. - Journal of Experimental Botany 61: 521-535. 
[25] Jamil, S., Ali, Q., Iqbal, M., Javed, M.T., Iftikhar, W., Shahzad, F. and Perveen, R. (2015): Modulations in plant water relations and tissue-specific osmoregulation by foliarapplied ascorbic acid and the induction of salt tolerance in maize plants. - Brazilian Journal of Botany 38(3): 527-538

[26] Julkenen-Titto, R. (1985): Phenolic constituents in the leaves of northern willows: methods for the analysis of certain phenolics. - Agriculture and Food Chemistry 33: 213217.

[27] Koca, H., Bor, M., Özdemir, F. and Türkan, I. (2007): The effect of salt stress on lipid peroxidation, antioxidative enzymes and proline content of sesame cultivars. Environmental and Experimental Botany 60: 344-351.

[28] Li, Y. (2009): Physiological responses of tomato seedlings (Lycopersicon esculentum) to salt stress. - Modern Applied Sciences 3: 171-176.

[29] Liang, Y., Chen, Q., Liu, Q., Zhang, W. and Ding, R. (2003): Exogenous silicon (Si) increases antioxidant enzyme activity and reduces lipid peroxidation in roots of saltstressed barley (Hordeum vulgare L.). - Journal of Plant Physiology 160(10): 1157-1164.

[30] Miller, G., Suzuki, N., Ciftci-Yilmaz, S. and Mittler, R. (2010): Reactive oxygen species homeostasis and signaling during drought and salinity stresses. - Plant Cell and Environment 33: 566-589.

[31] Mukherjee, S.P. and Choudhuri, M.A. (1983): Implication of water stress-induced changes in the levels of endogenous ascorbic acid and hydrogen peroxide in Vigna seedlings. - Plant Physiology 58: 166-170.

[32] Navarro, J.M., Flores, P., Garrido, C. and Martinez, V. (2006): Changes in the contents of antioxidant compounds in pepper fruits at different ripening stages, as affected by salinity. - Food Chemistry 96: 66-73.

[33] Noreen, S., Ashraf, M., Hussain, M. and Jami, 1.A. (2009): Exogenous application of salicylic acid enhances antioxidative capacity in salt stressed sunflower (Helianthus annuus L.) plants. - Pakistan Journal of Botany 41(1): 473-479.

[34] Pearson, G.A. and Ayers, A.D. (1960): Rice as a crop for salt-affected soil in process of reclamation. - USDA Production Research Report 43: 1-13.

[35] Posmyk, M.M., Kontek, R. and Janas, K.M. (2009): Antioxidant enzymes activity and phenolic compounds content in red cabbage seedlings exposed to copper stress. Ecotoxicology and Environmental Safety 72: 596-602.

[36] Rice-Evans, C.A., Miller, N.J. and Paganga, G. (1996): Structure-antioxidant activity relationships of flavonoids and phenolic acids. - Free Radical Biology and Medicine 20: 933-956.

[37] Roshandel, P. and Flowers, T. (2009): The ionic effects of $\mathrm{NaCl}$ on physiology and gene expression in rice genotypes differing in salt tolerance. - Plant and Soil 315: 135-147.

[38] Ruiz, J.M., Blasco, B., Rivero, R.M. and Romero, L. (2005): Nicotine-free and salttolerant tobacco plants obtained by grafting to salinity-resistant rootstocks of tomato. Physiologia Plantarum 124: 465-475.

[39] Sairam, R.K., Srivastava, G.C., Agarwal, S. and Meena, R.C. (2005): Differences in antioxidant activity in response to salinity stress in tolerant and susceptible wheat genotypes. - Biologiae Plantarum 49: 85-91.

[40] Shehab, G.G., Ahmed, O.K. and El-Beltagi, H.S. (2010): Effects of various chemical agents for alleviation of drought stress in rice plants (Oryza sativa L.). - Notulae Botanicae Horti Agrobotanici Cluj-Napoca 38(1): 139-148.

[41] Sheokand, S., Bhankar, V. and Sawhney, V. (2010). Ameliorative effect of exogenous nitric oxide on oxidative metabolism in $\mathrm{NaCl}$ treated chickpea plants. - Brazilian Journal of Plant Physiology 22: 81-90.

[42] Shi, Q., Ding, F., Wang, X. and Wei, M. (2007): Exogenous nitric oxide protects cucumber roots against oxidative stress induced by salt stress. - Plant Physiology and Biochemistry 45(8): 542-550. 
[43] Siân L. Richards, Katie A. Wilkins, Stéphanie M. Swarbreck, Alexander A. Anderson, Noman Habib, Alison G. Smith, Martin McAinsh, and Julia M. Davies. (2015): The hydroxyl radical in plants: from seed to seed. - Journal of Experimental Botany 66(1): 37 46.

[44] Tanou, G., Molassiotis, A. and Diamantidis, G. (2009): Hydrogen peroxideand nitric oxide-induced systemic antioxidant prime-like activity under $\mathrm{NaCl}$-stress and stress-free conditions in citrus plants. - Journal of Plant Physiology 166: 1904-1913.

[45] Velikova, V., Yordanov, I. and Edreva, A. (2000): Oxidative stress and some antioxidant systems in acid rain-treated bean plants. Protective role of exogenous polyamines. - Plant Science 151: 59-66.

[46] Yuan, G., Wang, X., Guo, R. and Wang, Q. (2010): Effect of salt stress on phenolic compounds, glucosinolates, myrosinase and antioxidant activity in radish sprouts. - Food Chemistry 121: 1014-1019.

[47] Zeng, C.L., Liu, L., Wang, B.R., Wu, X.M. and Zhu, Y. (2011): Physiological effects of exogenous nitric oxide on Brassica juncea seedlings under $\mathrm{NaCl}$ stress. - Biologiae Plantarum 55(2): 345-348.

[48] Zeng, L., Lesch, S.M. and Grieve, C.M. (2003): Rice growth and yield respond to changes in water depth and salinity stress. - Agricultural Water Management 59: 67-75.

[49] Zhang, F., Wang, Y., Yang, Y.L., Wu, H., Wang, D. and Liu, J.Q. (2007): Involvement of hydrogen peroxide and nitric oxide in salt resistance in the calluses from Populus euphratica. - Plant Cell and Environment 30: 775-785.

[50] Zhang, Y.Y., Wang, L.L., Liu, Y.L., Zhang, Q., Wei, Q.P. and Zhang, W.H. (2006): Nitric oxide enhances salt tolerance in maize seedlings through increasing activities of proton-pump and $\mathrm{Na}^{+} / \mathrm{H}^{+}$antiport in the tonoplast. - Planta 224: 545-555.

[51] Zhao, M.G., Tian, Q.Y. and Zhang, W.H. (2007): Nitric oxide synthase-dependent nitric oxide production is associated with salt tolerance in Arabidopsis. - Plant Physiology 144: 206-217.

[52] Zheng, C., Jiang, D., Liu, F., Dai, T., Liu, W., Jing, Q. and Cao, W. (2009): Exogenous nitric oxide improves seed germination in wheat against mitochondrial oxidative damage induced by high salinity. - Environmental and Experimental Botany 67(1): 222-227. 